\title{
EFEITOS DE REGULADORES VEGETAIS NO DESENVOLVIMENTO E NA PRODUTIVIDADE DO AMENDOINZEIRO (Arachis hypogaea L.)
}

\author{
P.R.C. CASTRO; B. APPEZZATO-DA-GLÓRIA \\ Departamento de Botanica - ESALQ/USP - C.P. 9 - CEP: 13418-900-Piracicaba,SP.
}

\begin{abstract}
RESUMO: O trabalho foi realizado com o objetivo de determinar a açāo de substâncias de crescimento no desenvolvimento e produtividade do amendoinzeiro, sob condições de casa de vegetação. Plantas de Arachis hypogaea cv. Tatu-53, providas de 4 folhas definitivas, foram pulverizadas com chlormequat 2000 ppm, daminozide 4000 ppm, ácido giberélico 100 ppm, ácido indolilacético 100 ppm, além do controle. Foram determinados: altura das plantas, número de hastes, número de entrenós, comprimento do segundo e quarto entrenós, e o número de folhas. Também foram verificados os numeros de flores, de frutos e de sementes; peso dos frutos, das sementes, da matéria seca da parte aérea e da matéria seca das raízes do amendoinzeiro. Os resultados obtidos revelaram que daminozide 4000 ppm reduziu a altura, o número de entrenós na haste principal e o comprimento do quarto entreno. Este produto também aumentou o número de folhas, atrasou a florescência, aumentou o número de flores e tendeu a aumentar o peso seco da parte aérea do amendoinzeiro. Pulverização com chlormequat $2000 \mathrm{ppm}$ e ácido indolilacético 100 ppm, diminuiu a altura da planta e o comprimento do quarto entrenó da haste principal do amendoinzeiro.

Descritores: reguladores de crescimento, amendoinzeiro.
\end{abstract}

\section{EFFECTS OF GROWTH REGULATORS ON GROUNDNUT DEVELOPMENT} (Arachis hypogaea L.)

\begin{abstract}
This research deals with the effects of plant growth regulators on grounduut growth (Arachis hypogaea L. cv. Tatu-53). Plants of groundnut with four leaves grown in pots under greenhouse conditions, were sprayed with chlormequat $2000 \mathrm{ppm}$, daminozide $4000 \mathrm{ppm}$, gibberellic acid $100 \mathrm{ppm}$, indolylacetic acid $100 \mathrm{ppm}$, and check treatment. Daminozide $4000 \mathrm{ppm}$ reduced plant height, internode number and the length of the fourth internode. Daminozide increased the number of leaves, retarded flowering, increased the number of flowers and presented a tendency to increase the dry weight of stems. Chlormequat $2000 \mathrm{ppm}$ and indolylacetic acid $100 \mathrm{ppm}$ reduced plant height and the lenght of the fourth internode of the groundnut plant stem.
\end{abstract}

Key Words: growth regulators, groundnut.

\section{INTRODUÇÃO}

$O$ amendoim tem adquirido importância à medida que seu óleo tem revelado alta qualidade e sua torta valor nutritivo reconhecido para uso como ração. $\mathrm{O}$ melhoramento genético do amendoinzeiro e a evolução das técnicas de cultivo têm levado a produtividades crescentes.

A utilização de novas técnicas culturais tem conduzido ao estudo dos efeitos de reguladores vegetais na produção do amendoinzeiro. Retardadores de crescimento têm-se mostrado eficientes em amendoinzeiro. Chlormequat tem ação de retardador de crescimento, por inibir a passagem de geranilgeranil pirofosfato para copalilpirofosfato, na biossíntese endógena de giberelinas. GUPTA (1975) verificou que chlormequat aumentou a porcentagem de casca e a umidade do fruto do amendoinzeiro 'Gambia'.
Chlormequat 500 ppm aumentou o número de frutos por hectare $\mathrm{e}$ as produções de amendoim em casca, em grãos, e de óleo por hectare. SINGH et al. (1978) observaram que aplicação de chlormequat 500 ppm, 50 dias após a semeadura, promoveu aumento na produção de amendoim em grãos. Uma aplicação foliar de chlormequat 1000 a 2000 ppm, 60 dias após a semeadura, aumentou a produção de grãos do cultivar Spanish Improved de 2,4 a 3,2-3,7 t/ha.

Pulverização com chlormequat aumentou - número de ramificações secundárias na planta, sendo que o retardador de crescimento aumentou a espessura foliar, a taxa de acumulação de matéria seca e a matéria seca total da planta (REDDY \& PATYL, 1981). Observou-se que aplicação de chlormequat, antes da florescência, retardou o crescimento da haste principal e das ramificações laterais. Ocorreu uma redução no número de nós e 
de folhas nas ramificações, além do decréscimo no tamanho dos folíolos e dos pecíolos. O retardador de crescimento aumentou o número de ramificações primárias e secundárias (NIGAM et al., 1983).

SORTE et al. (1989) realizaram aplicação de chlormequat 100 a 1000 ppm, 20 dias após a semeadura, em dois cultivares de amendoinzeiro. Observaram que aumentos na concentração do produto incrementaram o teor de clorofila nas folhas e reduziram o teor de açúcar em folhas e vagens, aumentaram o número de flores e vagens por planta. Chlormequat 500 e $1000 \mathrm{ppm}$ aumentou a produção em 7,6 e $15,9 \%$, respectivamente. Aplicação de reguladores vegetais em amendoinzeiro 'DH 3-30', 45 dias após a semeadura, mostrou maior eficiência do chlormequat. Verificou-se aumento no índice de área foliar, na produção de matéria seca, taxa assimilatória líquida e taxa de crescimento relativo; sendo que as produções atingiram $2,2 \mathrm{t} / \mathrm{ha}$, com relação a 1,7 t/ha do controle (NAWALAGATTI et al., 1991). Amendoinzeiro 'GG2' pulverizado com chlormequat 500 ppm, 25 e 50 dias após a semeadura, aumentou o índice de área foliar, peso da matéria seca, porcentagem de vagens, peso de 100 sementes e a produção (KELAIYA et al., 1991).

Daminozide é um retardador de crescimento que inibe a ação da triptamina oxidase e consequentemente a passagem de triptamina a 3indolilacetaldeído, na biossíntese endógena de ácido indolilacético. BAUMAN \& NODERN, (1971) notaram que daminozide reduziu o crescimento das hastes laterais, do caule principal e dos entrenós do amendoinzeiro. As plantas tratadas adquiriram uma coloração verde escura na folhagem, mas a produção não foi afetada. BROWN \& ETHREDGE (1974) verificaram que duas ou três aplicações de $1,43 \mathrm{~kg}$ de daminozide por hectare, 60 a 90 dias após a semeadura, no amendoinzeiro 'Starr', reduziram a altura da planta em 30 a $40 \%$, o comprimento do fruto de 4 a $10 \%$ e o comprimento do ginóforo em $4 \%$. Daminozide aumentou a produção de frutos em 1968, mas não em 19691970. O regulador de vegetal aumentou a razão fruto/palhada, mas não afetou a razão peso das hastes/planta, área foliar específica ou área dos folíolos. Verificou-se que a aplicação de $1 \mathrm{~kg} / \mathrm{ha}$ de daminozide, 40 a 45 dias após a semeadura, aumentou a produção de grãos em até $360 \mathrm{~kg} / \mathrm{ha}$, reduziu o peso de 100 sementes e o número de frutos vazios, incrementando a germinação das sementes e a produção dos cultivos obtidos com as sementes das plantas tratadas (BOCKELÉEMORVAN et al., 1975). Daminozide foi aplicado na dosagem de $0,95 \mathrm{~kg} / \mathrm{ha}$, ou quando necessário para manter as plantas menores do que $34 \mathrm{~cm}$, em diferentes épocas, em três cultivares de amendoinzeiro. A produção não foi afetada, mas o peso, comprimento e diâmetro do fruto, e o tamanho das sementes, decresceram com aplicação 6 a 10 semanas após a semeadura (DAUGHTRY et al., 1975). Aplicação da daminozide reduziu a altura do caule principal e o comprimento dos entrenós das ramificações, de diversos cultivares de amendoinzeiro, em todas as épocas de pulverização, mas pouco afetou o número de nós do caule principal e das ramificações. $O$ cultivar 'Valência Local' apresentou frutos mais compactos, mas o peso seco médio das sementes e o número de sementes por fruto foram ligeiramente reduzidos pelo retardador de crescimento (HAMMERTON, 1976). Daminozide aplicado com surfactante (agente capaz de aumentar a penetração do produto) não afetou a produção do amendoinzeiro, mas afetou a rapidez do crescimento foliar quando pulverizado no estágio inicial de desenvolvimento da planta (SANTELMANN \& THILSTED, 1977). Sob condições controladas, daminozide aplicado nas dosagens de 1,1 ou $2,2 \mathrm{~kg} / \mathrm{ha}$, em plantas de amendoinzeiro com 1 mês de idade, reduziu a altura das plantas. $O$ regulador vegetal aumentou o peso das raízes (WU \& SANTELMANN, 1977). Sob condições de campo, daminozide aplicado em pulverização única ou parcelada, reduziu significativamente o crescimento do amendoinzeiro, quando aplicado no final da florescência ou na produção de ginóforos. Não foram verificadas alterações significativas na produção (THILSTED \& SANTELMANN, 1977). Daminozide aplicado nos cultivares 'Dixie Runner' e 'Florunner' de amendoinzeiro, reduziu o comprimento da haste e produziu folhas mais verdes, sem afetar o índice de área foliar ou a iniciação floral. O retardador de crescimento aumentou a taxa de crescimento das vagens em ‘@'Dixie Runner`@’ e incrementou o número de vagens em ambos os cultivares (N'DIAYE, 1981). Pulverização foliar do amendoinzeiro 'Spanhish Improved', 60 dias após a semeadura, com daminozide 2000 a 4000 ppm, aumentou a produção de 2,4 a 3,6 a 4,3 tha, respectivamente. $O$ retardador diminuiu a altura da planta, aumentou o número de ramificações secundárias, índice de área foliar, espessura da folha, taxa de acumulação de matéria seca e a matéria seca total (REDDY \& PATYL, 1981). 
NIGAM et al. (1983) observaram que daminozide retardou o crescimento da haste principal e das ramificações laterais do amendoinzeiro. Verificouse uma diminuição no número de nós e folhas nas ramificações, além de uma redução no tamanho dos folíolos e dos pecíolos. Daminozide aumentou o número de ramificações primárias e secundárias. Efeitos de daminozide no amendoinzeiro se manifestaram 1 a 2 semanas após a aplicação. Observou-se encurtamento dos entrenós e um adensamento da folhagem. Uma única aplicação durante a máxima florescência $(60$ a 70 dias após a emergência), resultou um retardamento no crescimento durante o período de florescência. Uma segunda aplicação, na dosagem de $0,5 \mathrm{~kg} / \mathrm{ha}$, mostrou-se necessária, 3 semanas mais tarde, para controle de excessivo crescimento. $O$ comprimento médio das vagens foi reduzido em 1 a $2 \mathrm{~mm}$, mas a porcentagem de vagens grandes, assim como a produção total, não foram afetadas (OHALY, 1985). Cultivares Dixie Runner, Florunner' e Pronto, de amendoinzeiro, foram utilizados para aplicação de $0,5 \mathrm{~g} / \mathrm{l}$ de daminozide. Verificou-se que $o$ produto retardou o crescimento da haste principal, do ramo cotiledonar e do pecíolo em 'Dixie Runner' e 'Florunner'. Daminozide reduziu a produção de matéria seca, a área foliar, a razão parte área/raízes e aumentou o teor de clorofila nas folhas (GARDNER, 1988). GORBET \& KNAUFT (1990), trataram 10 cultivares de amendoinzeiro com três aplicações de daminozide $0,56 \mathrm{~kg} / \mathrm{ha}$, a partir de 55 dias após a semeadura, com 3 semanas de intervalo. Observaram-se significativas diferenças entre os cultivares em resposta ao retardador. Daminozide diminuiu o crescimento das hastes em todos os cultivares. 'Florigiant' produziu a melhor resposta ao produto, aumentando a produção em $666 \mathrm{~kg} / \mathrm{ha}$. 'UF 79308' mostrou um decréscimo na produçãa de vagens no mesmo período. Aumentou a porcentagem de sementes grandes em resposta a daminozide. O tipo Virginia revelou melhores respostas ao produto com relação ao tipo prostado (Runner).

Amendoinzeiros dos tipos Spanish e Virginia foram tratados com diferentes concentrações de ácido giberélico $\left(\mathrm{GA}_{3}\right)$, sob condições de vaso. $O$ produto promoveu um significativo alongamento das hastes sem alterar o número de entrenós. Esse efeito foi maior no estágio inicial, mostrando-se particularmente evidente no caule principal do cultivar semi-erecto e nas ramificações do cultivar prostrado (Virginia). $\mathrm{GA}_{3}$ aumentou o número de flores e de ginóforos proporcionalmente às concentrações aplicadas (1, 10,100 e $1000 \mathrm{ppm}$ ), mas esse efeito foi tardio (REBÉCHAULT \& GUÉNIN, 1967). Sementes de amendoinzeiro foram imersas em solução de $\mathrm{GA}_{3}$, $10 \mathrm{ppm}$ anteriormente ao plantio. $O$ promotor de crescimento aumentou o teor de óleo de sementes colhidas (RAO, 1975), Aplicação de $\mathrm{GA}_{3}$ aumentou a altura das plantas de amendoinzeiro (SURYANARAYANA, 1977). NIGAM et al. (1983) verificaram que aplicação de $\mathrm{GA}_{3}$ à folhagem das plantas de amendoinzeiro, antes da florescência, aumentou o comprimento da haste principal e das ramificações. $\mathrm{GA}_{3} 250$ e $500 \mu \mathrm{g} /$ planta aumentou o número de folhas da haste principal. O número de nós $\mathrm{e}$ folhas nas ramificações decresceu, sendo que o tamanho dos folíolos e dos pecíolos aumentou. O número de ramificações primárias e secundárias foi reduzido com a aplicação do produto. REDDY \& SHAH (1984) verificaram que a aplicação de $G_{3} 25$ e 50 ppm, em 4 cultivares de amendoinzeiro, aumentou significativamente o teor de óleo nas sementes e a produção de óleo. O teor de óleo nas sementes foi mais alto no tipo Spanhish Brunch, sendo que a produção de óleo mostrou-se superior no tipo Virginia Runner. Amendoinzeiro cultivar TG-1 foi pulverizado com $\mathrm{GA}_{3} 10^{-4} \mathrm{M}$, nos estágios de florescência e de produção dos ginóforos. Enquanto verificou-se aumento no peso das vagens, tamanho das sementes e em 2:1 na razão de vagens e sementes, observou-se redução no número de ginóforos e de vagens. O regulador mostrou-se mais eficiente quando aplicado no estágio de produção de ginóforos do que na florescência. A dependência do estágio para responder ao efeito do regulador vegetal é explicada em termos do nivel diferencial e efetivo de hormônios endógenos nos vários estágios de crescimento (MISHRA et al., 1984), podendo também ser explicado em função do número de receptores ao regulador vegetal, presentes nos diferentes estágios de desenvolvimento do tecido. Imersão das sementes de amendoinzeiro em $G_{3} 100 \mathrm{mg} / \mathrm{l}$, ou duas pulverizações foliares com ácido giberélico 10 $\mathrm{mg} / \mathrm{l}$, aumentaram significativamente a produção de vagens. $O$ regulador decresceu o teor de óleo na semente (SINGH \& RATHORE, 1987). $\mathrm{GA}_{3} 0,01$ e $0,1 \mathrm{~g} / 1$ foi aplicado em três cultivares de diferentes tipos de amendoinzeiro. $O$ regulador atuou positivamente no alongamento do pecíolo $\mathrm{e}$ alterou a distribuição de matéria seca, em favor das ramificações. 'Dixier Runner' respondeu menos ao produto do que 'Florunner'. A obscuridade 
estimulou mais o alongamento da haste do que o ácido giberélico; sendo que os dois efeitos são aditivos (GARDNER, 1988). GUNDALIA et al. (1990) realizaram duas aplicações foliares de $G_{3}$ 25 ou $50 \mathrm{ppm} \mathrm{em}$ amendoinzeiro. A produção foi de $27,9 \mathrm{~g}$ com $\mathrm{GA}_{3} 50 \mathrm{ppm}$, em relação a $20,0 \mathrm{~g}$ do controle. $O$ regulador aumentou o teor de óleo nas sementes. LEE (1990) efetuou a imersão de sementes de amendoinzeiro em soluções de $\mathrm{GA}_{3} 50$ e $100 \mathrm{ppm}$, antes da semeadura. Verificou o desenvolvimento de plantas com haste principal mais alta, maior número de ramificações e maior teor de clorofila, com relação ao controle. A emergência das plântulas e o tempo para florescência foram também melhorados com o tratamento das sementes com $\mathrm{GA}_{3}$. KELAIYA et al. (1991) aplicaram $\mathrm{GA}_{3} 20 \mathrm{ppm}$ em amendoinzeiro 'GG2', 25 e 50 dias após a semeadura. Observou-se aumento no índice de área foliar, peso da matéria seca, porcentagem de ginóforos e peso de 100 sementes. $O$ produto não aumentou o teor de óleo nas sementes.

Aumento na porcentagem de germinação de sementes e as maiores produções de amendoinzeiro, foram obtidas com aplicação de ácido indolilacético (IAA) $10 \mathrm{ppm}$. O tratamento também incrementou a produção de óleo (SANJEEVAIAH et al., 1967). Duas aplicações de ácido naftalenacético (NAA) $40 \mathrm{ppm}$ no amendoinzeiro, 40 e 80 dias após a semeadura, produziram 1537 $\mathrm{kg}$ de grãos/ha, $78,4 \%$ de frutos com sementes e $51,5 \%$ de óleo nas sementes, com relação a 1095 $\mathrm{kg}, 68,4$ e $48,5 \%$, respectivamente, no controle (GOPALAKRISHNAN \& SRINIVASAN, 1975).

Foram realizadas pulverizações em amendoinzeiro com NAA 0 a 160 ppm, 40 e 60 dias após a semeadura. A auxina sintética a $40 \mathrm{ppm}$ promoveu aumento no peso dos nódulos e no conteúdo de nitrogênio e carboidratos na planta. $O$ número de nódulos foi maior nas plantas tratadas com NAA 20 a 40 ppm. (SRINIVASAN \& GOPALAKRISHNAN, 1977). REDDY (1978) verificou em experimentos com três cultivares de amendoinzeiro, pulverizando NAA 20 a $60 \mathrm{ppm}$, que o cultivar semi-prostrado produziu 9 a $18 \%$ a mais do que o cultivar prostrado $(2,32 \mathrm{t} / \mathrm{ha})$ e o cultivar de moita $(2,18 \mathrm{t} / \mathrm{ha})$, respectivamente. As maiores produções do cultivar semi-prostrado foram dadas pelos maiores pesos dos frutos maduros/planta, maior índice de área foliar, maior peso seco e melhor alocação aos frutos. As produções médias foram maiores com aplicação de NAA $40 \mathrm{ppm}$. SINGH \& SHARMA (1982) efetuaram duas aplicações foliares de NAA $10 \mathrm{ppm}$ em amendoinzeiro, 40 e 50 dias após a semeadura. Notaram aumento no número de ginóforos e de vagens por planta, na produção de vagens secas e no peso de 100 sementes; sendo que a porcentagem de casca e o teor de óleo na semente, não foram afetados. REDDY \& SHAH (1984) observaram que aplicação de NAA 25 e $50 \mathrm{ppm}$, em amendoinzeiro, aumentou o teor de óleo na semente, sendo que NAA $50 \mathrm{ppm}$ promoveu 0 maior incremento em óleo. Duas aplicações foliares de NAA aumentaram significativamente a produção de vagens no amendoinzeiro (SAGARE \& NAPHADE, 1987). A imersão de sementes de amendoinzeiro em IAA $100 \mathrm{mg} / \mathrm{l}$ ou a aplicação de duas pulverizações foliares com IAA $15 \mathrm{mg} / \mathrm{l}$, aumentaram significativamente a produção de vagens. IAA aumentou 0 teor de óleo nas sementes. As aplicações foliares de IAA produziram os valores mais altos de produção e de conteúdo de óleo (SINGH \& RATHORE, 1987). DEVASENAPATHY et al. (1987) pulverizaram amendoinzeiros, uma única vez (45 dias após a semeadura) e duas vezes (aos 45 e 55 dias), com NAA $40 \mathrm{ppm}$. O cultivar $\mathrm{CO} 1$ produziu mais vagens por planta do que 'JL 24', sendo que 'TMV 7', com duas aplicações de NAA, teve a maior produção. Este desempenho se modificou no ano seguinte. GUNDALIA et al. (1990) notaram que duas aplicações foliares de NAA ou $80 \mathrm{ppm}$, em amendoinzeiro, levaram a uma produção de 21,9 a $30,9 \mathrm{~g}$ de vagens em relação a $20,0-20,9 \mathrm{~g}$ do controle. LEE (1990) realizou a imersão de sementes de amendoinzeiro em soluções de IAA 50 a $200 \mathrm{ppm}$. Verificou aumento na altura da haste principal, maior número de ramificações, maior conteúdo de clorofila, maior número de flores, entrenós e vagens; além de maior peso de grãos por planta. A emergência da plântula $e$ o tempo para a florescência foram também melhorados com o tratamento das sementes. NAWALAGATTI et al. (1991) pulverizaram amendoinzeiro ' $\mathrm{DH}$ 3-30', 45 dias após a semeadura, com NAA 10 ou $20 \mathrm{ppm}$. Observaram aumento no índice de área foliar, produção de matéria seca, taxa assimilatória líquida, taxa de crescimento relativo e na produção de vagens. KELAIYA et al. (1991) notaram que o amendoinzeiro 'GG2' pulverizado com NAA 40 $\mathrm{ppm}$, apresentou uma produção de vagens de 1,06 t/ha, comparada com 0,97 a $0,98 \mathrm{t} / \mathrm{ha}$ dos demais tratamentos. Aplicação do regulador, 25 e 50 dias após a semeadura, aumentou o índice de área foliar, peso da matéria seca, porcentagem de casca 
e o peso de 100 sementes. NAA aumentou o teor de óleo nas sementes.

O objetivo deste trabalho foi verificar os efeitos de reguladores vegetais no crescimento, florescência e produtividade do amendoinzeiro cultivar Tatu-53, sob condições de casa-devegetação.

\section{MATERIAL E METODOS}

Iniciou-se o ensaio em 14 de fevereiro, em condições de casa-de-vegetação, realizando-se a semeadura do amendoinzeiro (Arachis hypogaea cv. Tatu-53), diretamente em vasos contendo 12 litros de terra com 1,9\% de carbono orgânico; $\mathrm{pH}$ 7,2; $\mathrm{Al} \mathrm{e} \mathrm{Ca}+\mathrm{Mg}$ nos teores de, respectivamente, 0,0 e 5,4 e. $\mathrm{mg} / 100 \mathrm{ml}$ de T.F.S.A.; finalmente 0,2 e 0,1 e.mg/100 $\mathrm{ml}$ de T.F.S.A., de $\mathrm{K}$ e P, respectivamente. As aplicações dos reguladores vegetais foram efetuadas em 01 de março, através de pulverização, até que as folhas estivessem completamente molhadas; no momento da aplicação, as plantas mostravam quatro folhas definitivas. Além do tratamento controle, foram aplicados chlormequat [(cloreto (2-cloroetil) trimetilamônio (CCC))] na concentração de 2000 ppm, daminozide (ácido succínico-2,2dimetilhidrazida (SADH)) 4000 ppm, ácido giberélico $\left(\mathrm{GA}_{3}\right) 100 \mathrm{ppm}$ e ácido indolilacético (IAA) 100 ppm.

Foi utilizado o delineamento experimental iriteiramente casualizado, com seis repetições, tendo-se mantido duas plantas por vaso e por repetição. Realizou-se a comparação de médias pelo Teste de Tukey, calculando-se a diferença mínima significativa a nível de $5 \%$ de probabilidade. Os parâmetros analisados referem-se a altura das plantas 60 dias após a semeadura $(60$ d.a.s.), número de hastes (74 d.a.s.), diâmetro do caule (60 d.a.s.), número de entrenós (60 d.a.s.), comprimento do segundo e quarto entrenós (60 d.a.s.), e ao número de folhas (60 d.a.s.). Também verificou-se o número de flores ( $35 \mathrm{~d}$.a.s.), número de frutos por planta (60 d.a.s.), número de sementes (133 d.a.s.), e também nessa data o peso dos frutos, peso das sementes, peso da matéria seca da parte aérea e o peso da matéria seca das raízes do amendoinzeiro 'Tatu-53'.

\section{RESULTADOS E DISCUSSÃO}

Pela TABELA 1, notamos que a altura das plantas de Arachis hypogaea observada 60 d.a.s. foi significativamente reduzida pelo tratamento com daminozide 4000 ppm. Pulverização com chlormequat 2000 ppm ou IAA $100 \mathrm{ppm}$, também diminuíram a altura das plantas de amendoinzeiro com relação ao controle e ao tratamento com $\mathrm{GA}_{3} 100 \mathrm{ppm}$. A maior resposta da planta ao efeito da daminozide, um retardador de crescimento que afeta a síntese de ácido indolilacético, sugere a importância dessa auxina endógena para o crescimento do caule, sendo que a redução no crescimento, provocada pelo ácido indolilacético exógeno, vem corroborar a afirmativa anterior, pois isso pode estar relacionado com acúmulo excessivo do regulador de crescimento.

Sabe-se que concentrações muito altas dc auxina, em função da sensibilidade (número de receptores) do tecido vegetal, podem levar a biossíntese endógena de etileno, capaz de produzir efeito retardador. A ação retardante da auxina mostrou-se similar ao efeito retardador do chlormequat (um inibidor da biossíntese endógena de GA), o que sugere uma importância relativa das giberelinas endógenas no processo de crescimento da haste do amendoinzeiro.

Diminuição na altura do amendoinzeiro por efeito do daminozide, foi também verificada por BAUMAN \& NORDEN (1971), BROWN \& ETHREDGE(1974), BOCKELEE-MORVANet al. (1975), DAUGHTRY et al. (1975), HAMMERTON (1976), WU \& SANTELMANN (1977); THILSTED \& SANTELMANN (1977), N'DIAYE (1981), NIGAM et al. (1983), GARDNER (1988) e GORBET \& KNAUFT (1990). Redução na altura da planta provocada por chlormequat também foi notada por NIGAM et al. (1983).

A diminuição da altura causada por auxina não parece ter sido observada anteriormentc, sendo que LEE (1990), ao contrário, notou aumento na altura da haste principal de amendoinzeiros originários de sementes imersas em solução de IAA.

Aplicação de $\mathrm{GA}_{3}$ não incrementou a altura do amendoinzeiro 'Tatu-53' em relação ao controle, sendo que a literatura geralmente assinala o efeito desse regulador vegetal no alongamento das hastes.

Os reguladores vegetais aplicados não afetaram o número de hastes da planta aos 74 d.a.s., indicando que não atuaram efetivamente na dominância apical, sendo que o diâmetro do caule 60 d.a.s., também não foi alterado pelas 
substâncias de crescimento (TABELA 1).

Notamos pela TABELA 1 que 0 tratamento com daminozide reduziu, 60 d.a.s., o número de entrenós da haste principal do amendoinzeiro em relação ao controle, indicando a forma com que o retardador de crescimento afetou o crescimento das plantas. HAMMERTON (1976) observou que daminozide pouco afetou o número de nós no caule principal e das ramificações ao amendoinzeiro; sendo que NIGAM et al. (1983) verificaram uma redução no número de nós provocada pelo daminozide.

Observado 60 d.a.s., o comprimento do segundo entrenó não foi afetado pelos reguladores vegetais; sendo que os tratamentos com daminozide e chlomequat reduziram o comprimento do quarto entrenó, e o daminozide mostrou um efeito retardante mais eficiente (TABELA 1). BAUMAN \& NORDEN, (1971), HAMMERTON (1976) e OHALY (1985) notaram diminuição no comprimento dos entrenós de amendoinzeiro tratado com daminozide.

A pequena redução no comprimento do quarto entrenó causada pelo chlormequat e pelo IAA, confirmam seus efeitos na diminuição da altura da planta.

O número de folhas, observado 60 d.a.s., foi incrementado pelo tratamento com daminozide (TABELA 1). Esse fato pode estar relacionado com aumentos na eficiência folossintética e na produtividade do amendoinzeiro. Aumentos no número de folhas $\mathrm{e}$ índice de área foliar do amendoinzeiro, foram também verificados por REDDY \& PATHIL (1981) e OHALY (1985).

Pela TABELA 2, notamos que o número de flores abertas, 35 d.a.s., revelou-se mais baixo nas plantas tratadas com daminozide. Este fato se deve a um atraso na florescência, provocado pelo regulador vegetal, uma vez que 40 d.a.s., essas plantas apresentavam florescência superior aos demais tratamentos (Figura 1). N'DIAYE (1981) não observou alteração na iniciação floral de amendoinzeiros tratados com daminozide.

Verificamos, na colheita (133 d.a.s.), que a aplicação dos reguladores vegetais não afetou o número de frutos, número de sementes, peso dos frutos, peso das sementes, nem o peso das raízes do amendoinzeiro. BAUMAN \& NORDEN (1971), DAUGHTRY et al. (1975), não notaram aumento na produção do amendoinzeiro tratado com reguladores vegetais.

Observamos porém, que a aplicação de daminozide aumentou o peso da matéria seca da parte aérea com relação ao tratamento com ácido indolilacético (TABELA 2). Isto pode estar relacionado com o aumento no número de folhas proporcionado pelo daminozide com relação às plantas tratadas com ácido indolilacético.

Aumentos no peso de amendoinzeiros tratados com daminozide foram notados por REDDY \& PATIL (1981); sendo que GARDNER (1988) observou redução na produção de matéria seca em plantas tratadas com daminozide.

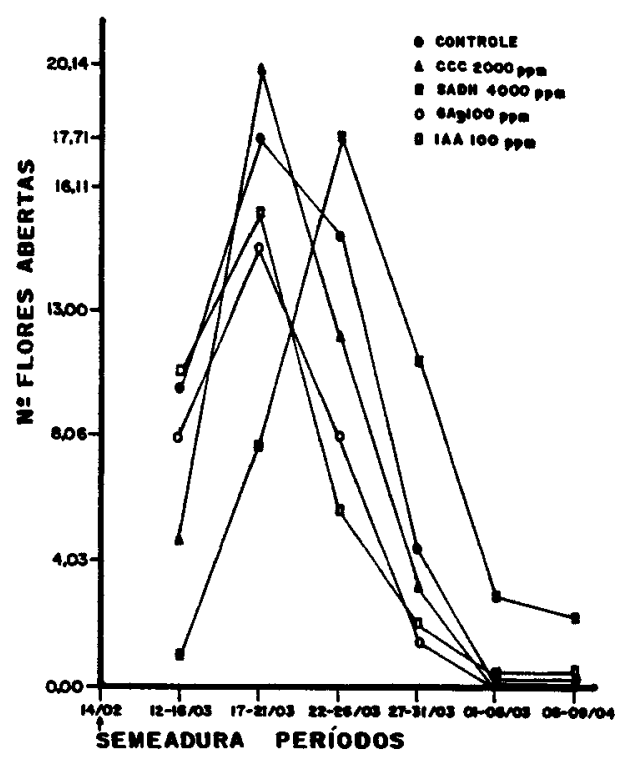

Figura 1 - Efeito de reguladores vegetais no número de flores abertas do amendoinzeiro 'Tatu-53', no decorrer do período de florescência da planta.

\section{CONCLUSÕES}

- A aplicação de daminozide 4000 ppm em plantas de Arachis hypogaea cv. Tatu-53, com quatro folhas definitivas, reduz a altura, o número de entrenós no caule principal e o comprimento do quarto entrenó.

- Daminozide 4000 ppm aumenta o número de folhas, atrasa a florescência, aumenta o número de flores e tende a aumentar o peso da matéria seca da parte aérea do amendoinzeiro 'Tatu-53'.

- Pulverização com clormequat 2000 ppm e ácido indolilacético $100 \mathrm{ppm}$ diminui a altura da planta e o comprimento do quarto entrenó da haste principal do amendoinzeiro. 
TABELA 1 - Efeitos da aplicação de reguladores vegetais na altura (cm, tomada 60 d.a.s.), número de hastes (transf. $x^{1 / 2}, 74$ d.a.s.), diâmetro do caule (cm, 60 d.a.s.), número de entrenós $\left(x^{1 / 2}, 60\right.$ d.a.s.), comprimento do segundo e quarto entrenós ( $\mathrm{cm}, 60$ d.a.s.) e no número de folhas $\left(x^{1 / 2}, 60\right.$ d.a.s.) do amendoinzeiro Tatu-53. Valores de F, Tukey (5\%) e coeficiente de variação.

\begin{tabular}{|c|c|c|c|c|c|c|c|}
\hline \multirow[t]{2}{*}{ Tratamentos } & \multirow[t]{2}{*}{ Altura } & \multirow{2}{*}{$\begin{array}{l}\text { número } \\
\text { hastes }\end{array}$} & \multirow{2}{*}{$\begin{array}{c}\text { diâmetro } \\
\text { caule }\end{array}$} & \multirow{2}{*}{$\begin{array}{l}\text { número } \\
\text { entrenós }\end{array}$} & \multicolumn{2}{|c|}{ comprimento entrenós } & \multirow{2}{*}{$\begin{array}{l}\text { número } \\
\text { folhas }\end{array}$} \\
\hline & & & & & segundo & quarto & \\
\hline Controle & $50,50 a$ & 2,07 & 4,73 & $3,50 \mathrm{ab}$ & 4,64 & $6,07 \mathrm{a}$ & $7,01 \mathrm{~b}$ \\
\hline CCC 2000 ppm & $43,71 \mathrm{~b}$ & 2,06 & 4,67 & $3,59 a b$ & 5,00 & $4,19 \mathrm{~b}$ & $7,16 \mathrm{~b}$ \\
\hline SADH $4000 \mathrm{ppm}$ & $22,90 \mathrm{c}$ & 2,23 & 4,70 & $2,92 \mathrm{c}$ & 4,03 & $1,56 \mathrm{c}$ & $8,43 \mathrm{a}$ \\
\hline $\mathrm{GA}_{3} 100 \mathrm{ppm}$ & $50,90 \mathrm{a}$ & 2,03 & 4,66 & $3,61 \mathrm{a}$ & 4,44 & $6,44 \mathrm{a}$ & $7,05 \mathrm{~b}$ \\
\hline IAA $100 \mathrm{ppm}$ & $44,21 \mathrm{~b}$ & 1,99 & 4,69 & $3,42 \mathrm{~b}$ & 3,47 & $5,23 \mathrm{~b}$ & $6,89 \mathrm{~b}$ \\
\hline F (trat.) & $63,44 * *$ & $2,24^{\text {nas }}$ & $0,05^{\mathrm{na}}$ & $36,67^{* *}$ & $1,30^{\mathrm{ns}}$ & $54,89 * *$ & $5,83 * *$ \\
\hline C.V. $(\%)$ & 8,93 & 7,71 & 6,72 & 3,59 & 31,50 & 14,86 & 9,47 \\
\hline
\end{tabular}

ns = não significativo

** = significativo ao nível de $1 \%$ de probabilidade

TABELA 2 - Efeitos da aplicação de reguladores vegetais no número de flores (transf. $(x-0,5)^{1 / 2}, 35$ d.a.s.), número de frutos por planta $\left(x^{1 / 2}, 60\right.$ d.a.s.), número de sementes $\left(x^{1 / 2}, 133\right.$ d.a.s. $)$, peso dos frutos $(\mathrm{g})$, peso das sementes $(\mathrm{g})$, peso da matéria seca das raízes $(\mathrm{g})$, do amendoinzeiro 'Tatu53'. Valores de F, Tukey (5\%) e coeficiente de variação.

\begin{tabular}{lccccccc}
\hline \hline \multirow{2}{*}{ Tratamentos } & $\begin{array}{c}\text { número } \\
\text { flores }\end{array}$ & $\begin{array}{c}\text { número } \\
\text { frutos }\end{array}$ & $\begin{array}{c}\text { número } \\
\text { sementes }\end{array}$ & $\begin{array}{c}\text { peso } \\
\text { frutos }\end{array}$ & $\begin{array}{c}\text { peso } \\
\text { sementes }\end{array}$ & $\begin{array}{c}\text { peso parte } \\
\text { aérea }\end{array}$ & $\begin{array}{c}\text { peso } \\
\text { raízes }\end{array}$ \\
\hline Controle & $2,51 \mathrm{a}$ & 3,38 & 5,99 & 20,55 & 15,93 & $13,71 \mathrm{ab}$ & 27,10 \\
CCC 2000 ppm & $2,54 \mathrm{a}$ & 3,93 & 6,44 & 24,30 & 18,54 & $14,69 \mathrm{ab}$ & 30,53 \\
SADH 4000 ppm & $1,64 \mathrm{~b}$ & 3,64 & 6,27 & 22,74 & 17,17 & $19,76 \mathrm{a}$ & 31,44 \\
GA $100 \mathrm{ppm}$ & $2,27 \mathrm{ab}$ & 3,36 & 5,58 & 18,88 & 14,21 & $13,33 \mathrm{ab}$ & 21,90 \\
IAA 100 ppm & $2,41 \mathrm{ab}$ & 3,76 & 6,34 & 21,47 & 16,36 & $12,49 \mathrm{~b}$ & 25,74 \\
\hline F (trat.) & $3,13^{*}$ & $1,78^{\mathrm{ns}}$ & $1,66^{\mathrm{ns}}$ & $1,63^{\mathrm{ns}}$ & $1,89^{\mathrm{ns}}$ & $3,19 *$ & $2,29^{\mathrm{ns}}$ \\
C.V. (\%) & 24,42 & 13,50 & 11,58 & 19.86 & 18,67 & 28,82 & 24,62 \\
\hline \hline
\end{tabular}

ns = não significativo

** = significativo ao nível de $5 \%$ de probabilidade

Sci. agric., Piracicaba. 50(2):176-184, jum./set., 1993 


\section{REFERENNCIAS BIBLIOGRÁFICAS}

BAUMAN, R.W.; NORDEN, A.J. Effect of growth regulators on vegetative and reproductive characteristics of six peanut genotypes. Joumal of the American Peanut Research and Education Association, Florida, v.3, n.1, p.75-86, 1971.

BOCKELÉE-MORVAN, A.; GILLIER, P.; ROUSSEL, O.; SALINS, J.F. Effect of a growth regulator on the yield and quality of various groundnut cultivars. Oléagineaux, Paris, v.30, n.7, p.311-317, 1975.

BROWN, R.H.; ETHREDGE, W.J. Effects of succinic acid 2,2-dimethylhydrazide on yield and other characteristics of peanut cultivars. Peanut Science, Raleigh, v.1, n.1, p.20-23, 1974.

DAUGHTRY, C.S.; BROWN, R.H.; ETHREDGE, W.J. Effect of time of application of succinic acid 2,2dimethylhydrazide on yields and associated characteristics. Peanut Science, Raleigh, v.2, n.2, p. 83-86, 1975.

DEVASENAPATHY, P.; JAGANNATHAN, N.T.; SUBBIAH, K.K. Effect of naphthalene acetic acid on grandnut. Indian Journal of Agronomy, New Delhi, v.32, n.2, p.176-177, 1987.

GARDNER. F.P. Growth and partitioning in peanut as influenced by gibberellic acid and daminozide. Agronomy Joumal, Madison, v.80, n.2, p.159-163, 1988.

GOPALAKRISHNAN, S.; SRINIVASAN, P.S. Effect of Planofix-an NAA formulation on groundnut. Indian Journal of Agricultural Chemistry, Allahabad, v.8, n.1/2, p.163-166, 1975 .

GORBET, D.W.; KNAUFT, D.A. Agronomic response of Virginia and Runner market type peanuts to the growth regulator SADH. Proceedings - SOIL CROP SCIENCE SOCIETY OF FLORIDA, Gainesville, v.49, p.132-134, 1990.

GUNDALIA, J.D.; PATEL, M.S.; PATEL, M.H.; VADHER, P.G. Groundnut response to growth regulators. Journal of Research Gujarat Agricultural University, Gujarat, v.16, n.1, p.60-62, 1990.

GUPTA, D.K.D. Effects of cycocel on crop plants in Sierra Leone. 1. Groundnut (Arachis hypogaea). Experimental Agriculture, Cambridge, v.11, n.3, p.209-213, 1975.

HAMMERTON, J.L. Effects of B-9 (N-dimethylaminosuccinamic acid) on growth and yield of peanuts (Arachis hypogaea L.). Journal of Agricultural Science, Cambridge, v.86, n.1, p.211-218, 1976.
KELAIYA, V.V.; JETHWA, M.G.; PATEL, J.C.; SADARIA, S.G. Effect of growth regulators and their spraying schedules on groundnut. Indian Journal of Agronomy, New Delhi, v.36, n.1, p.111113, 1991.

LEE, H.S. Effects of pre-sowing seed treatments with $G_{3}$ and IAA on flowering and yield components in groundnuts. Korean Journal of Crop Science, Suwon, v.35, n.1, p.1-9, 1990.

MISHRA, S.D.; JOSHI, R.K.; GAUR, B.K. Preferential effect of GA, BA and ethrel at pegging stage in groundnut (Arachis hypogaea L.). Acta Botanica Indica, Meerut, v.12, n.2, p.123-128, 1984.

NAWALAGATTI, C.M.; PANCHAL, Y.C.; MANJUNATH, S.; CHANNAPPAGOUDAR, B.B. Effects of different levels of plant growth regulators on growth and yield of groundnut. Journal of Maharashtra Agricultural Universities, Pune, v.16, n.1, p.122-123, 1991

N'DIAYE, O. Physiological aspects of peanut (Arachis hypogaea L.) yield as effected by daminozide. Dissertation Abstracts Internationl, Ann Arbor, v.41, n.9, p.3264-3265, 1981 .

NIGAM, R.K.; VARKEY, M.; REUBEN, D.E. Effects of gibberellic acid B-9 and CCC on the growth and flower sex in Arachis hypogaea. Indian Journal of Agricultural Research, Haryana, v.17, n.1/2, p.1724,1983 .

OHALY, J. Daminozide a growth regulator for peanuts. Phytoparasitica, Rehovot, v.13, n.3/4, p.236, 1985.

RABÉCHAULT, H.; GUÉNIN, G. Effects of GA on two groundnut varieties. Cahiers ORSTOM. Série Biologie, France, v.4, n.4, p.3-29, 1967.

RAO, S.P. Effects of seed treatment with phytohormones on seed yield and quality of peas and groundnuts. Indian Journal of Agricultural Research, Haryana, India, v.9, n.3, p.121-126, 1975.

REDDY, S.C.V. Growth and yield of groundnut varieties (Arachis hypogaea Linn.) in relation to the application of naphthalene acetic acid. India, 1978. 229p. Thesis - University of Agricultural Sciences, Bangalore.

REDDY, S.C.V.; PATIL, S.V. Effect of growth retardants on the yield and yield attributes of groundnut (Arachis hypogaea L.). Mysore Journal Agricultural Sciences, Bangalore, v.15, n.2, p.238-241, 1981

REDDY, C.S.; SHAH, C.B. Influence of growth regulators on seed oil content and oil yield of Spanish Bunch and Virginia Runner cultivars of groundnut 
(Arachis hypogaea L.). Seed \& Farms, India, v.10, n.11, p.21-24, 1984 .

SAGARE, B.N.; NAPHADE, K.T. Effect of hormones on yield, economics and nutrient uptake by ground nut Arachis hypogaea L.. PKV Research Journal, Pune, v.11, n.1, p.19-22, 1987.

SANJEEVAIAH, B.S.; PHANISHAYI, G.; RAJASHE KARA, B.G. Response of groundnut (Arachis hypogaea L.) to plant growth regulators. Mysore Journal of Agricultural Sciences, Bangalore, v.1, n.2, p.81-87, 1967.

SANTELMANN, P.; THILSTED, E. Plant growth regulator use in Spanish peanuts. Caddo Research Station Report, Oklahoma, p.754, 1977.

SINGH, K.; RATHORE, S. Groundnut yield response to treatments with plant growth substances. Indian Agriculturist. Calcutta, v.31, n.3. p.177-180, 1987.

SINGH, G.; SHARMA, B. Effect of growth regulators on groundnut productivity. Indian Journal of Ecology, Punjab, v.9. n.2. p.281-285, 1982.

SINGH, G.: SEKHON, N.: KAUR, M. Effect of growth-regulators on some yield-contributing parameters in Arachis hypogaea L. Journal of Research, Ludhiana, v.15, n.12, p.106-111, 1978.
SORTE, N.V.; DEOTALE, R.D.; RATNAPARKHI, V.P.; SHASTRI, N.R. Effect of foliar application of Cycocel on peanut (Arachis hypogaea L.). Annals of Plant Physiology, Maharashtra, v.3, n.2, p.203-211, 1989.

SRINIVASAN, P.S.; GOPALAKRISHNAN, S. Effect of Planofix-an NAA formulation on groundnut var. TMV-7. Current Science, Bangalore, v.46, n.4, p.119-120, 1977.

SURYANARAYANA, Y. Effect of growth regulators of growth, development and yield of groundnut. Thesis Abstracts, Haryana, v.3, n.4, p.252, 1977.

THILSTED, E.; SANTELMANN, P.W. Comparison of mefluidide, ethephon, and SADH in Spanhish peanuts. In: PLANT GROWTH REGULATOR WORKINC GROUP, 4., 1977, Arkansas. Proceedings... Hol Springs: Arkansas, 1977, p.353

WU, C.H.; SANTELMANN, P.W. Influence of six plant growth regulators on Spanish peanuts. Agronomy Journal, Madison, v.69, n.3, p.521-522, 1977.

Trabalho enviado para publicaçāo em 03.04.91 Trabalho aceito para publicação em 18.02 .93 